\title{
Hydrogen Gas Sensors Using Two-Dimensional Electron Gas
}

\author{
Se Eun Kim, Hye Ju Kim and Sang Woon Lee \\ Department of Energy Systems Research and Department of Physics, Ajou University \\ Suwon 16499, Republic of Korea \\ kimss3381@ajou.ac.kr; ajuphysics@ajou.ac.kr; slee01@ajou.ac.kr
}

\section{Extended Abstract}

Hydrogen $\left(\mathrm{H}_{2}\right)$ has been considered as a clean and environment-friendly energy source on account of its low ignition energy and high heat of combustion from which the combustion product is $\mathrm{H}_{2} \mathrm{O}$.[1] Recently, $\mathrm{H}_{2}$ gas is regarded as the most important energy source for the operation of electrical vehicles. [2, 3] However, $\mathrm{H}_{2}$ is not only flammable but also explosive in the concentration of 4-75\%. Unfortunately, it is impossible to detect $\mathrm{H}_{2}$ gas by human beings because of its colorless and odorless property. Therefore, a development of sensitive $\mathrm{H}_{2}$ gas sensor is required for human safety.[4,5]

Two-dimensional electron gas (2DEG) was observed at the interface of oxide heterostructure in 2004.[6] The model system for 2DEG at the oxide heterostructure is epitaxial interface of $\mathrm{LaAlO}_{3} / \mathrm{SrTiO}_{3}$ heterostructure. Recently, we reported that 2DEG can be created at the oxide heterostructure by using amorphous $\mathrm{Al}_{2} \mathrm{O}_{3}$ top layer.[7] Here, we demonstrate highperformance $\mathrm{H}_{2}$ gas sensor using 2DEG at the interface of $\mathrm{Al}_{2} \mathrm{O}_{3} / \mathrm{SrTiO}_{3}$ heterostructure using atomic layer deposition (ALD). Palladium (Pd) or platinum (Pt) catalysts are used on top of the $\mathrm{Al}_{2} \mathrm{O}_{3} / \mathrm{SrTiO}_{3}$ heterostructure.[8] At first, we will show a $\mathrm{H}_{2}$ gas sensing performance using $2 \mathrm{DEG}$ at the interface of $\mathrm{Al}_{2} \mathrm{O}_{3} / \mathrm{SrTiO}_{3}$ heterostructure. The $\mathrm{H}_{2}$ gas sensor using $\mathrm{Al}_{2} \mathrm{O}_{3} / \mathrm{SrTiO}_{3}$ exhibited a wide sensing range of $\mathrm{H}_{2}$ concentration (5ppm-1\%) even room temperature with fast response time. The more $\mathrm{H}_{2}$ gas concentration increased, the more $\mathrm{H}_{2}$ gas sensitive increased. The $\mathrm{Pd} / \mathrm{Al}_{2} \mathrm{O}_{3} / \mathrm{SrTiO}_{3}$ sensor showed a fast response time to detect $\mathrm{H}_{2}$ gas $(<30 \mathrm{~s})$ at room temperature. Owing to a wide bandgap $(>3.2 \mathrm{eV})$ of $\mathrm{Al}_{2} \mathrm{O}_{3} / \mathrm{SrTiO}_{3}$, a transparent gas sensor (transmittance $>83 \%$ in the visible spectrum) was realized. 2DEG resistance is changed by adsorbing $\mathrm{H}_{2}$ gas because the work function of $\mathrm{Pd}$ nanoparticles is modulated by the $\mathrm{H}_{2}$ adsorption. Alteration of work function induced the change of the 2DEG resistance. The detailed detection principle will be explained in the presentation.

$\mathrm{H}_{2}$ gas sensor using 2DEG at heterostructure such as $\mathrm{AlGaN} / \mathrm{GaN}$ is another candidate for $\mathrm{H}_{2}$ detection, thus, $\mathrm{H}_{2}$ sensor using $\mathrm{AlGaN} / \mathrm{GaN}$ is compared with $\mathrm{Al}_{2} \mathrm{O}_{3} / \mathrm{SrTiO}_{3}$ sensor. $\mathrm{H}_{2}$ gas sensor using $\mathrm{AlGaN} / \mathrm{GaN}$ heterostructure showed a slow $\mathrm{H}_{2}$ detection speed, but superior sensitivity ( 30000\%) compared to the $\mathrm{Al}_{2} \mathrm{O}_{3} / \mathrm{SrTiO}_{3}$ sensor. In addition, enhanced detection performances of $\mathrm{H}_{2}$ gas sensor with $\mathrm{AlGaN} / \mathrm{GaN}$ heterostructures using atomic-layer-thick $\mathrm{ZnO}$ on Pt (or Pd) on 2DEG are addressed, which improved a decrease of recovery time. The atomic-layer-thick ZnO layer was grown by ALD which will be introduced in the presentation.

\section{References}

[1] S. Sharma, S. K. Ghoshal, "Hydrogen the future transportation fuel: From production to applications," Renewable and Sustainable Energy Reviews, 2015, vol. 43, pp. 1151-1158. A. Ohtomo, H. Hwang, Nature 2004, 427, 423.

[2] S. Dunn, "Hydrogen futures: towards a sustainable energy system," International Journal of Hydrogen Energy, vol. 27, pp. 235-264, 2002.

[3] P. P. Edwards, V. L. Kuznetsov, W. I. David, N. P. Brandon, "Hydrogen and fuel cells: towards a sustainable energy future," Energy Policy, vol. 36, p. 4356, 2008.

[4] H. Purwanto, T. Akiyama, "Hydrogen production from biogas using hot slag," International Journal of Hydrogen Energy, vol. 31, pp. 491-495, 2006.

[5] H. Gu, Z. Wang, Y. Hu, "Hydrogen Gas Sensors Based on Semiconductor Oxide Nanostructures," Sensors, vol. 12, pp. 5517-5550, 2012.

[6] A. Ohtomo, H. Hwang, Nature, vol. 427, p. 423, 2004.

[7] S. W. Lee, Y. Liu, J. Heo, R. G. Gordon, Nano Lett., vol. 12, p. 4775, 2012. 
[8] C.-Y. Lee, C.-M. Chiang, Y.-H. Wang, R.-H. Ma, "A self-heating gas sensor with integrated NiO thin-film for formaldehyde detection," Sensors and Actuators B: Chemical, vol. 122, pp. 503-510, 2007. 